\title{
Psychological, Peer, and Family Influences on Smoking Among an Adolescent Psychiatric Sample
}

\author{
Jessica E. Nargiso, Ph.D., \\ The Warren Alpert Medical School of Brown University, Providence, RI 02912 \\ Sara J. Becker, Ph.D., \\ The Warren Alpert Medical School of Brown University, Providence, RI 02912 \\ Jennifer C. Wolff, Ph.D., \\ The Warren Alpert Medical School of Brown University, Providence, RI 02912
}

Kristen M. Uhl, B.A.,

The Warren Alpert Medical School of Brown University, Providence, RI 02912

Valerie Simon, Ph.D.

Wayne State University, Detroit, MI 48202

Anthony Spirito, Ph.D., and

The Warren Alpert Medical School of Brown University, Providence, RI 02912

Mitchell J. Prinstein, Ph.D.

University of North Carolina, Chapel Hill, NC 27599

\begin{abstract}
While much is known about adolescent cigarette use and initiation in community samples, less is known about these factors among adolescents in clinic-referred populations or those with severe psychopathology. Data were collected from 106 adolescents aged 12 to 15 years $(M=13.6 ; S D=$. 74) recruited from a psychiatric inpatient facility. Hierarchical logistic regressions assessed the relationship between psychological, peer, and family environment factors and smoking at baseline and 18 months post-hospitalization. Conduct problem symptoms, friends' cigarette use, and friends' marijuana use were associated with greater odds of lifetime and current smoking at baseline, but not at follow-up. After accounting for the significant effect of baseline use, greater family conflict predicted decreased odds of having initiated smoking at the 18 month follow-up. The period following inpatient psychiatric hospitalization may represent an important window for smoking cessation and prevention efforts targeting peer and family factors, especially for youth with externalizing problems.
\end{abstract}

\section{Keywords}

adolescence; smoking; psychiatric comorbidity; peer influence; family environment

\footnotetext{
(C) 2011 Elsevier Inc. All rights reserved.

Corresponding author: Jessica E. Nargiso, Ph.D., Warren Alpert Medical School of Brown University, Box G-S121-4, Providence, RI 02912, Jessica_Nargiso@ brown.edu, Phone: (401) 863-6629, Fax: (401) 863-6647.

Publisher's Disclaimer: This is a PDF file of an unedited manuscript that has been accepted for publication. As a service to our customers we are providing this early version of the manuscript. The manuscript will undergo copyediting, typesetting, and review of the resulting proof before it is published in its final citable form. Please note that during the production process errors may be discovered which could affect the content, and all legal disclaimers that apply to the journal pertain.
} 


\section{Introduction}

Despite substantial declines in cigarette use over the last 15 years, smoking remains a prevalent health problem among teenagers. Evidence suggests that nearly $90 \%$ of smoking initiation occurs during adolescence (U.S. Department of Health and Human Services, 1994) and that the earlier one begins smoking, the less likely one is to successfully quit (Breslau \& Peterson, 1996; Coambs, Li, \& Kozlowski, 1992). Nationally, approximately $7 \%$ of $8^{\text {th }}$ graders, $13 \%$ of tenth graders and $20 \%$ of twelfth graders have smoked a cigarette in the past 30 days (Johnston, O’Malley, Bachman, \& Schulenberg, 2010). Rates are even higher in adolescents with emotional and/or behavioral disorders. In one study of 120 early adolescents admitted to a psychiatric inpatient unit (Mean age $=13.7, S D=2.5$ ), 53\% of adolescents reported lifetime smoking and 39\% endorsed current smoking (Upadhyaya, Brady, Wharton, \& Liao, 2003). Another study of older adolescent psychiatric inpatients (Mean age $=15.3, S D=1.4$ ) found still higher rates, with nearly $60 \%$, of the sample endorsing current smoking (Ramsey, Brown, Strong, \& Sales, 2002).

Parental and family factors have been identified as key proximal predictors of adolescent smoking (Avenevoli \& Merikangas, 2003) and are particularly influential during early adolescence. Factors such as high parental monitoring, parental involvement, and disapproval of smoking have been found to lower the risk of tobacco use in teens (Darling \& Cumsille, 2003; Hill, Hawkins, Catalano, Abbott, \& Guo, 2005; Simons-Morton, 2002, 2004). Parental involvement and expectations have also been found to decrease the likelihood of smoking among $7^{\text {th }}$ graders, in spite of increasing peer pressure to smoke (Simons-Morton, 2002, 2004). Conversely, several characteristics of the family environment have been shown to increase the odds of smoking (Darling \& Cumsille, 2003; Isohanni, Moilanen, \& Rantakallio, 1991; Tilson, McBride, Lipkus, \& Catalano, 2004). In a number of studies, family environments characterized by less cohesion, support and expressiveness, and greater levels of family conflict have been associated with higher levels of adolescent tobacco use (Biglan, Duncan, Ary, \& Smolkowski, 1995; Brook, Zhang, Finch, \& Brook, 2010; Duncan, Tildesley, Duncan, \& Hops, 1995; Glendinning, Shucksmith, \& Hendry, 1997; Kristjansson, Sigfusdottir, Allegrante, \& Helgason, 2009).

Empirical data also identifies peers as one of the most significant factors associated with adolescent smoking (Kobus, 2003). The influence of peer smoking is multi-faceted. Both the number of peers who smoke and peer approval of smoking are positively related to smoking initiation in teens (Mayhew, Flay, \& Mott, 2000). In a study of 4,263 eighth-grade students, teens with one tobacco-using friend were 2.73 times more likely to smoke, while teens with two or more tobacco-using friends were 9.46 times more likely to smoke than teens who were not friends with smokers (Simons-Morton \& Farhat, 2010). Additionally, peer group socialization and selection of friends have both been related to smoking among teenagers (Ennett \& Bauman, 1994; Go, Green, Kennedy, Pollard, \& Tucker, 2010; Hoffman, Monge, Chou, \& Valente, 2007). For example, teen smokers tend to associate with other smokers, while nonsmokers tend to affiliate with other non-smokers (Kobus, 2003). Although the relationship between peer and family factors is complex, several studies have provided evidence suggesting that peer variables exert a greater influence on adolescent smoking outcomes than family characteristics (Flay et al., 1994; Hu, Flay, Hedeker, Siddiqui, \& Day, 1995; Simons-Morton \& Farhat, 2010; Tucker, Ellickson, \& Klein, 2003; Wang, Fitzhugh, Westerfield, \& Eddy, 1995).

In addition to peer and family factors, individual psychological factors have also been linked to adolescents' smoking behaviors in both community and clinical samples (Covey, Glassman, \& Stetner, 1998; Hawkins, Catalano, \& Miller, 1992; Turner, Mermelstein, \& Flay, 2004). Major depressive disorder (MDD) and conduct problem disorders (including 
oppositional defiant disorder and conduct disorder) represent two conditions that have demonstrated a significant relationship with smoking (Brown, Lewinsohn, Seeley, \& Wagner, 1996; Duncan \& Rees, 2005; Fergusson, Goodwin, \& Horwood, 2003; Prinstein \& La Greca, 2009; Turner, et al., 2004). Both cross-sectional analyses and longitudinal studies have found depression to be a risk factor for as well as a result of smoking (Brown, et al., 1996; Simons-Morton, 2002; Windle \& Windle, 2001). Similarly, conduct problems have been found to increase an adolescent's risk of early smoking initiation, current smoking, and the development of nicotine dependence (Chilcoat \& Breslau, 1999; Lambert \& Hartsough, 1998; Milberger, Biederman, Faraone, Chen, \& Jones, 1997; Ramsey et al., 2003; Riggs, Mikulich, Whitmore, \& Crowley, 1999; Upadhyaya, et al., 2003).

While a substantial body of knowledge exists on smoking in community samples of adolescents, considerably less is known regarding the role of peer influences, family factors, and psychopathology on smoking among adolescents being treated for psychiatric disorders (Avenevoli \& Merikangas, 2003; Kobus, 2003; Mayhew, et al., 2000). Several studies have examined rates of smoking among adolescent psychiatric inpatients, but have not examined the predictive effects of other salient factors (Ramsey, et al., 2002; Ramsey, et al., 2003; Upadhyaya, et al., 2003). Thus, this paper examines how psychological, peer and family factors influence current cigarette use and initiation of use in adolescents upon psychiatric inpatient admission as well as at 18 months following hospitalization. This study was guided by three primary hypotheses. First, we expected that mental health problems (depression and conduct problems) at baseline would be positively associated with an increased likelihood of lifetime and current cigarette use at baseline and follow-up. Second, we expected peer substance use and family environment variables to predict increased likelihood of lifetime and current cigarette use at both time points, beyond the effects of the individual psychological variables. Finally, we expected that peer influences would have a greater effect on smoking outcomes than family environment variables.

\section{Methods}

The methods for this study have been described in a prior publication (Prinstein et al., 2008). Participants in the initial study included 146 psychiatrically hospitalized adolescents. The measure of cigarette use was not administered at the start of the study and, consequently, data on this measure are not available for the entire sample. The current sample therefore consisted of 106 adolescents (67\% female) between the ages of 12 and 15 years ( $M=13.6$, $S D=.74$ ), with complete baseline data on cigarette use. The sample was $80 \%$ Caucasian, 4\% Hispanic, $1 \%$ African American, 1\% Asian American, and 14\% Other/More than Race.

Participants were recruited from a psychiatric inpatient facility in the northeastern United States. All adolescents admitted to the unit were eligible for study participation, provided that they had sufficient cognitive functioning to complete a structured interview (e.g. no active psychosis or developmental delay). Consistent with institutional review board approved procedures, adolescents and their parents were invited to participate in this study shortly after admission to the unit. After providing written consent and assent, adolescents and their parents were separately administered a comprehensive assessment battery. All assessment measures were read aloud to adolescents during one-on-one interviews conducted by trained staff. Adolescents completed smoking questions again at 9 and 18 months post-baseline.

\subsection{Measures}

Child Depression Inventory-(CDI; (Kovacs, 1992). The CDI is a 27-item paper and pencil questionnaire that served as the measure of depressive symptoms. For each item, the adolescent was presented with three statements representing varying levels of 
symptomatology. The adolescent was asked to choose the statement that best described him/ her over the past two weeks. An overall CDI score was calculated as the sum of the individual items, with higher scores indicating higher levels of depressive symptoms. Adequate reliability for the CDI for both boys and girls across several age groups (coefficient alphas ranging from .83 to .89) has been established (Smucker, Craighead, Craighead, \& Green, 1986). Internal consistency in the current sample was .87.

NIMH Diagnostic Interview Schedule for Children-(DISC-IV; (Shaffer, Fisher, Lucas, Dulcan, \& Schwab-Stone, 2000). The DISC-IV was used to calculate adolescent- and parent-reported symptoms of conduct problems. The DISC-IV is a highly structured diagnostic interview that reliably assesses common mental health disorders using DSM-IV criteria in children and adolescents (Shaffer, et al., 2000). Both the parent and youth versions were administered as part of this study. Composite symptom scores were calculated separately for the youth and parent versions by tallying the total number of symptoms endorsed on both the oppositional defiant disorder and conduct disorder sections of the DISC-IV. In prior psychometric testing, Shaffer and colleagues (2000), found that test-retest reliability was somewhat higher for the youth version than the parent version for major depressive disorder (adolescent version kappa $=.92$, parent version kappa $=.66$ ) and conduct disorder $(\mathrm{kappa}=.65$, parent version kappa $=.43)$, whereas reliability for the youth and parent versions was similar for oppositional defiant disorder (adolescent version kappa $=.51$, parent version kappa =. 54) (Shaffer et al., 2000).

Health Risk Behaviors (HRB) Questionnaire-The HRB is a self-report measure based on the Youth Risk Behavior Surveillance Survey (YRBS; (Centers for Disease Control and Prevention, 1998) that assesses history of alcohol, cigarette, and marijuana use. For the current study, we examined two questions related to smoking. Participants were asked whether or not they had ever used cigarettes and how frequently they had smoked over the past 30 days. Adolescents who reported any prior use of cigarettes were defined as lifetime smokers, while adolescents who reported any prior use of cigarettes over the past 30 days were defined as current smokers. These items have previously demonstrated good testretest reliability over a two week period among a national sample of adolescents (kappa values were .86 for lifetime cigarette use and .82 for current cigarette use) (Brener et al., 2002).

Deviant Peer Group Affiliation (DPGA) Questionnaire-The DPGA is a self-report measure that was developed for a previous study (Prinstein, Boergers, \& Spirito, 2001) as an extension of existing measures of peer affiliation. As in previous measures of deviant peer affiliation (e.g., Dishion, Patterson, Stoolmiller, \& Skinner, 1991; Fergusson \& Horwood, 1996), participants are first asked to identify the number of people they consider to be "very close friends." Adolescents are then asked how many of these friends engaged in substance use and other risky behaviors. For each item, a ratio between 0 and 1.0 was calculated to reflect the proportion of identified close friends who engaged in the risky behavior. Each ratio was then centered and divided by the standard deviation of that item in order to create a standardized score. The current study examined only the four items that assessed substance use. Three of the items assessed peer use of cigarettes, alcohol, and marijuana, and a fourth item assessed peer disapproval of substance use. Prinstein and colleagues (2001) examined the factor structure of this questionnaire and determined that these four items loaded on a single factor.

Family Environment Scale-(FES). The FES is a 90-item, true/false, parent-report measure that assesses various characteristics of family relationships. The FES has been used previously in studies of adolescent substance initiation and use (Ary, Duncan, Duncan, \& 
Hops, 1999; Duncan, et al., 1995; Foxcroft \& Lowe, 1995; Santisteban et al., 2003). The Relationship dimension of the FES consists of three subscales: Cohesion, Expressiveness, and Conflict (Moos \& Moos, 1981). In prior studies, the reliability of the FES Relationship dimension has been shown to vary by subscale (Boyd, Gullone, Needleman, \& Burt, 1997; Moos \& Moos, 1981). The cronbach alpha values for the current sample were: Cohesion $=$. 79 , Expressiveness $=.48$, Conflict $=.79$, which were consistent with the reliability estimates found by Boyd and colleagues (1997). Due to the low reliability of the Expressiveness scale, only the Cohesion and Conflict scales were used in the current analysis.

\subsection{Missing Data}

Because the current analyses only contained two time intervals, imputation of missing 18month data was not justified. Analyses were therefore conducted using only adolescents with complete data on the outcome variables. For the baseline regression analyses, the sample consisted of 106 adolescents with complete baseline cigarette use measures. Individuals with missing lifetime smoking data at 18 months who reported having initiated smoking at baseline were coded as lifetime smokers at follow-up. For the 18 month regression analyses, there were 81 adolescents with complete data on the measure of past 30-day cigarette use and 93 adolescents with complete data on lifetime cigarette use. Those adolescents with missing data at the 18 month follow up did not differ from the full baseline sample on any of the study variables, providing no evidence of attrition bias.

\subsection{Analysis Plan}

Two sets of analyses were designed to test the study hypotheses. The first set of analyses examined predictors of smoking at baseline, while the second set examined predictors of smoking over the 18 month study follow-up. For each set of analyses, two dependent variables from the HRB Questionnaire were examined: current cigarette use (any cigarette use over the past 30 days) and lifetime cigarette use (any history of use). Hierarchical logistic regressions with sequential testing of blocks of predictor variables were used to test the study hypotheses. All analyses were conducted using SPSS 17.0 (SPSS Inc., 2009). In the analysis design, the demographic variables of age and gender were entered in Block 1 and psychological variables (baseline depression score, and conduct problem symptom scores) were entered into Block 2. The effects of close peers' use of cigarettes, alcohol, and marijuana as well as peer disapproval of use were entered in Block 3. To enable a direct comparison of the importance of family environment versus peer factors, scores of family cohesion and conflict were also entered in Block 3 of the regression equation. For the 18 month analyses, baseline current cigarette use was included in Block 1 of the first logistic regression model and baseline lifetime cigarette use was included in Block 1 of the second logistic regression. By including baseline smoking status in the first block to account for individuals who had already initiated use at the start of the study, the logistic regression examining lifetime smoking at 18 months essentially allowed us to examine whether any other of the baseline factors predicted smoking initiation over the 18 months following hospitalization.

\section{Results}

Thirty-six percent of the sample reported current smoking (defined as having at least one cigarette in the past 30 days) and half endorsed a lifetime history of smoking (defined as having smoked at least one whole cigarette) at baseline (see Table 1).

At the 18 month follow-up, 51\% of the sample reported current smoking and $77 \%$ of the sample reported a lifetime history of use, indicating that $28 \%$ of teens had initiated use over the 18 months following hospitalization. Table 2 summarizes the predictor variables at 
baseline. Thirty two percent of the sample met criteria for a diagnosis of major depressive disorder at baseline, and $32 \%$ of the sample met criteria for a diagnosis of a conduct problem disorder (oppositional defiant disorder and/or conduct disorder). Adolescents reported significantly fewer mean number of overall conduct problem symptoms $(M=3.34, S D=$ 3.47) compared to parent reported symptoms $(M=6.20, S D=3.65 ; t=8.17$, $\mathrm{df}=105, p<$. $001)$; the correlation between these measures was moderate $(r=.49, p<.05)$, suggesting that they are related, yet independent measures of adolescent conduct problems. Mean FES scores were not in the clinical range for either of the subscales. No significant differences were found between girls and boys on the study variables.

\subsection{Predictors of Baseline Smoking}

Current use-The first cross-sectional hierarchical logistic regression analysis examined demographic, psychological, peer and family-level predictors of current cigarette use (Table $3)$. Age and gender were not significantly associated with current smoking. Of the psychological predictors, only adolescent reported conduct problem symptoms demonstrated a trend towards significance with current smoking $(\mathrm{p}=.05$, OR $=1.19)$. In addition, having close friends who smoke cigarettes and marijuana (but not alcohol) significantly increased adolescents' odds of current smoking (ORs of 2.02 and 1.98 respectively). None of the family environment scales were significantly associated with current use.

Lifetime use-The second cross-sectional hierarchical logistic regression analysis examined the influence of the same set of predictor variables on lifetime smoking. Adolescent-reported conduct problem symptoms was the only psychological predictor associated with greater odds of lifetime smoking at baseline $(\mathrm{OR}=1.22)$. Similar to the analysis of current use, close friends' use of cigarettes and marijuana (but not alcohol) also significantly increased adolescents' odds of lifetime cigarette use (ORs of 2.81 and 2.29 respectively). Again, none of the demographic or family environment scales were associated with lifetime use.

\subsection{Predictors of Smoking at 18 Months}

Current use-Hierarchical logistic regression examined whether the same set of demographic, psychological, peer, and family-level variables predicted current cigarette use (past 30 day use) at the 18 month follow-up (Table 4). Current cigarette use at baseline significantly accounted for current smoking at 18 months. Adolescents who reported current use at baseline experienced a nearly nine-fold increase in the odds of current smoking at 18 months relative to adolescents who did not report current smoking at baseline $(\mathrm{OR}=8.97)$. Contrary to our hypotheses, none of the demographic, psychological, peer use, or family environment variables were significantly associated with current smoking at 18 months when accounting for baseline status.

Lifetime use-Another hierarchical logistic regression analysis examined lifetime history of cigarette use at the 18 month follow-up. This analysis enabled us to identify predictors of smoking initiation over the year and a half following inpatient hospitalization. None of the demographic, psychological or peer influence variables significantly predicted lifetime cigarette use, after accounting for baseline status. Family conflict emerged as a significant, but modest predictor of lifetime cigarette use; however, the relationship was in the opposite direction than was predicted. Higher levels of family conflict were associated with a decrease in the odds of having initiated smoking over the 18 month follow-up period $(\mathrm{OR}=$. 92). 


\section{Discussion}

The current paper examined the effects of psychological, peer, and family environment factors on adolescent smoking in a severe psychiatric population. Rates of lifetime and current cigarette use in this sample of psychiatrically hospitalized adolescents were significantly higher than those reported in national community samples of youth. For example, the 2009 National Survey of Drug Use \& Health found that 9\% of 12 to 17 year olds identified as current smokers (Substance Abuse and Mental Health Services Administration, 2010), while the 2010 Monitoring the Future Study found that only $7 \%$ of $8^{\text {th }}$ graders reported current smoking (Johnston, et al., 2010). The high rates of current and lifetime smoking in the current sample are consistent with the high rates of smoking reported in other psychiatric samples of adolescents (Ramsey, et al., 2002; Upadhyaya, et al., 2003; Upadhyaya, Deas, Brady, \& Kruesi, 2002).

Results of this study provided partial support for our three hypotheses. Consistent with our first hypothesis, we found that youth with a greater number of self-reported conduct problems were $22 \%$ more likely to report lifetime smoking at baseline. Additionally, there was a trend $(\mathrm{p}=.05)$ between conduct problem symptoms and an increase in the odds of current smoking at baseline. Of note, these findings were not replicated when using the measure of parent-reported conduct problems, and were not replicated at the 18 month follow-up point. Parents reported significantly greater rates of conduct problem behavior than youth reported (approximately double the rates of oppositional defiant disorder and/or conduct disorder), which may have resulted in reduced variability in the predictor and limited our ability to detect significant findings.

Contrary to our expectations, depressive symptoms were not significantly associated with adolescent smoking at baseline or at 18 months for this psychiatric inpatient sample. Although this finding was inconsistent with longitudinal studies documenting a positive association between depression and adolescent smoking, several studies have found that the size of the relationship is diminished when accounting for common confounding factors (Duncan \& Rees, 2005; Fergusson, et al., 2003; Prinstein \& La Greca, 2009). Additionally, one of the few studies examining smoking outcomes in a sample of psychiatrically hospitalized adolescents similarly failed to find a significant association between depression and smoking (Ramsey, et al., 2003). Current study findings suggest that severity of conduct problems, but not depression, was a significant risk factor for smoking among adolescents presenting for inpatient hospitalization.

In support of our second hypothesis, we found that close friends' use of certain substances substantially increased adolescents' odds of being a lifetime or current smoker at baseline. Specifically, close friends cigarette and marijuana use were significantly associated with current smoking as well as a lifetime history of smoking. Consistent with findings from community samples (Alexander, Piazza, Mekos, \& Valente, 2001; Holliday, Rothwell, \& Moore, 2010; Kobus, 2003; Simons-Morton \& Farhat, 2010), these findings support the critical role of peer substance use in influencing adolescent smoking. Relative to other predictors, cigarette smoking by close friends resulted in the largest increase in the odds for lifetime and current use at baseline. Notably, friends' drinking was not a significant risk factor for adolescent smoking at baseline, suggesting it is not peer substance use in general that increases adolescents' odds of smoking, but that there may be specificity regarding the means of consumption (e.g. smoking vs. drinking). Results of our baseline analyses further indicated that peer engagement in current substance use was a more important predictor than peer disapproval of substance use. Contrary to our hypotheses, none of the peer variables was associated with smoking at 18 months when accounting for baseline status. 
Finally, we had hypothesized that peer variables would have a greater effect than family variables on smoking outcomes within this high risk sample of adolescents. Results of our baseline analysis provided support for this hypothesis, and were consistent with existing literature documenting the consistent and potent effect of close peers' use on teen smoking (Conrad, Flay, \& Hill, 1992; Kobus, 2003; Tyas \& Pederson, 1998). At baseline, close friends' use was significantly associated with smoking outcomes, while family environment variables (e.g., cohesion and conflict) did not have a significant effect.

A different pattern of results emerged at the 18-month follow-up. After accounting for baseline smoking status, family conflict was the only variable that significantly predicted lifetime smoking at 18-months. Of note, the relationship was in the opposite direction than was predicted. Reporting greater amounts of family conflict at baseline predicted a modest decrease in odds of initiating smoking at the 18 month follow-up. This finding is inconsistent with other naturalistic longitudinal research demonstrating that greater family cohesion and lower amounts of family conflict are associated with lower rates of tobacco and other substance use during adolescence (Bray, Adams, Getz, \& Baer, 2001; Gutman, Eccles, Peck, \& Malanchuk, 2011; Latendresse et al., 2008; Lloyd-Richardson,

Papandonatos, Kazura, Stanton, \& Niaura, 2002). However, the degree of family conflict reported in the current sample $(M=58.34, S D=13.72)$ was below the empirically-derived clinical threshold (Moos \& Moos, 1981). Therefore, it is possible that the amount of conflict reported in this sample is not indicative of clinically elevated family problems that would be expected to require intervention or predict negative outcomes. Instead, the greater conflict reported in this sample may reflect appropriate family disagreements or expressions of frustration. An alternate consideration is that parents who more openly express disagreements or conflict with their child may be more likely to provide strong discipline, which has also been associated with decreased substance use among adolescents (Fletcher \& Jefferies, 1999; Latendresse, et al., 2008). Future research should explore whether the same relationship is evident among families with clinically-elevated levels of family conflict.

\subsection{Limitations}

Findings of the current study must be interpreted within the context of potential limitations. First, the small sample size may have limited the ability to detect significant findings. Second, while several of the psychological and peer factors demonstrated significant associations with lifetime and current smoking at baseline, these analyses were crosssectional and therefore preclude interpretations of causality. Third, the high rates of cigarette use in the sample at baseline may have inhibited our ability to find significant differences in the sample at the 18-month follow-up. Fourth, the dichotomous nature of the dependent variables enabled us to examine predictors of smoking initiation and any amount of current smoking, which has been relatively understudied in this population. However, future research should explore whether the same prediction pattern is found when examining other measures of smoking and smoking dependency, such as frequency of days smoked or quantity of cigarettes smoked per day. Finally, the sample was predominantly female (72\%) and therefore potential gender differences could not be examined. Some research suggests differential predictors by gender (Gutman, et al., 2011; Mercken, Snijders, Steglich, Vertiainen, \& de Vries, 2010) and future research should examine whether gender moderates the effect of psychological, peer, and family factors on smoking outcomes among adolescents with severe psychopathology.

\subsection{Clinical Implications}

Adolescents with co-occurring psychiatric disorders have high smoking rates (Brown, Madden, Palenchar, \& Cooper-Patrick, 2000; Upadhyaya, et al., 2002) and may represent a subpopulation with particularly high risk of continued smoking as adults (Myers \& Brown, 
1997; Rohde, Kahler, Lewinsohn, \& Brown, 2004). Psychiatric hospitalization represents a window of opportunity to implement cessation and prevention efforts among this high risk population. In one of the only studies to examine the process of quitting among adolescents following psychiatric hospitalization, MacPherson and colleagues (2007) found that adolescents who attempted to quit in the first week following hospitalization demonstrated less average smoking over a 12 month follow-up period compared to adolescent smokers who did not make an attempt during this period. However, adolescents who attempted to quit immediately following hospitalization demonstrated a marked increase in smoking within the first few months following treatment (MacPherson et al., 2007). This finding suggests that the time period during and immediately following hospitalization represents an important window for cessation efforts and that a greater intensity or duration of treatment may be necessary for this high risk group (Brown et al., 2003). Additionally, the period following an acute hospitalization may represent an opportunity for targeted prevention efforts for adolescents who have not initiated smoking. Family or parent education and intervention programs may be especially important for adolescents with mental health disorders (Hall \& Prochaska, 2009). Taken together, results of our baseline and 18 month analyses indicate that smoking cessation and selected prevention efforts should address both peer and family factors in order to reduce the high rates of smoking in early adolescents with significant psychiatric problems, particularly those that endorse externalizing disorders. Parents in particular need to be aware of the high rates of cigarette smoking in this population and the potential role that family environment may play in initiation of smoking.

\section{Acknowledgments}

This work was supported by grant 1R01MH59766 through the National Institute of Mental Health which funded the research study described in this manuscript. The preliminary results of this manuscript were previously presented in poster format at the 2011 annual conference for the Society for Research on Nicotine and Tobacco.

\section{References}

Alexander C, Piazza M, Mekos D, Valente T. Peers, schools, and adolescent cigarette smoking. Journal of Adolescent Health. 2001; 29(1):22-30. [PubMed: 11429302]

Ary DV, Duncan TE, Duncan SC, Hops H. Adolescent problem behavior: the influence of parents and peers. Behaviour Research and Therapy. 1999; 37(3):217-230. [PubMed: 10087640]

Avenevoli S, Merikangas KR. Familial influences on adolescent smoking. Addiction. 2003; 98(Suppl 1):1-20. [PubMed: 12752359]

Biglan A, Duncan TE, Ary DV, Smolkowski K. Peer and Parental Influences on Adolescent Tobacco Use. Journal of Behavioral Medicine. 1995; 18(4):315-330. [PubMed: 7500324]

Boyd CP, Gullone E, Needleman GL, Burt T. The Family Environment Scale: Reliability and Normative Data for an Adolescent Sample. Family Process. 1997; 36(4):369-373. [PubMed: 9543658]

Bray JH, Adams GJ, Getz JG, Baer PE. Developmental, family, and ethnic influences on adolescent alcohol usage: a growth curve approach. Journal of Family Psychology. 2001; 15(2):301-314. [PubMed: 11458635]

Brener ND, Kann L, McManus T, Kinchen SA, Sundberg EC, Ross JG. Reliability of the 1999 youth risk behavior survey questionnaire. Journal of Adolescent Health. 2002; 31(4):336-342. [PubMed: 12359379]

Breslau N, Peterson EL. Smoking cessation in young adults: Age at initiation of cigarette smoking and other suspected influences. American Journal of Public Health. 1996; 86(2):214-220. [PubMed: 8633738]

Brook JS, Zhang CS, Finch SJ, Brook DW. Adolescent Pathways to Adult Smoking: Ethnic Identity, Peer Substance Use, and Antisocial Behavior. American Journal on Addictions. 2010; 19(2):178186. [PubMed: 20163390] 
Brown C, Madden PAF, Palenchar DR, Cooper-Patrick L. The association between depressive symptoms and cigarette smoking in an urban primary care sample. International Journal of Psychiatry in Medicine. 2000; 30(1):15-26. [PubMed: 10900558]

Brown RA, Lewinsohn PM, Seeley JR, Wagner EF. Cigarette smoking, major depression, and other psychiatric disorders among adolescents. Journal of the American Academy of Child and Adolescent Psychiatry. 1996; 35(12):1602-1610. [PubMed: 8973066]

Brown RA, Ramsey SE, Strong DR, Myers MG, Kahler CW, Lejuez CW, Niaura R, Pallonen UE, Kazura AN, Goldstein MG, Abrams DB. Effects of motivational interviewing on smoking cessation in adolescents with psychiatric disorders. Tobacco Control. 2003; 12(Suppl 4):IV3-10. [PubMed: 14645934]

Centers for Disease Control and Prevention. Youth-risk behavior surveillance-United States, 1997. Morbidity and Mortality Weekly Report. 1998; 47:SS-3.

Chilcoat HD, Breslau N. Pathways from ADHD to early drug use. Journal of the American Academy of Child and Adolescent Psychiatry. 1999; 38(11):1347-1354. [PubMed: 10560220]

Coambs RB, Li S, Kozlowski LT. Age Interacts with Heaviness of Smoking in Predicting Success in Cessation of Smoking. American Journal of Epidemiology. 1992; 135(3):240-246. [PubMed: 1546699]

Conrad KM, Flay BR, Hill D. Why children start smoking cigarettes: predictors of onset. British Journal of Addiction. 1992; 87:1711-1724. [PubMed: 1490085]

Covey LS, Glassman AH, Stetner F. Cigarette smoking and major depression. Journal of Addictive Diseases. 1998; 17(1):35-46. [PubMed: 9549601]

Darling N, Cumsille P. Theory, measurement, and methods in the study of family influences on adolescent smoking. Addiction. 2003; 98(Suppl 1):21-36. [PubMed: 12752360]

Dishion TJ, Patterson GR, Stoolmiller M, Skinner ML. Family, School, and Behavioral Antecedents to Early Adolescent Involvement with Antisocial Peers. Developmental Psychology. 1991; 27(1): 172-180.

Duncan B, Rees DI. Effect of smoking on depressive symptomatology: A reexamination of data from the national longitudinal study of adolescent health. American Journal of Epidemiology. 2005; 162(5):461-470. [PubMed: 16076832]

Duncan TE, Tildesley E, Duncan SC, Hops H. The Consistency of Family and Peer Influences on the Development of Substance Use in Adolescence. Addiction. 1995; 90(12):1647-1660. [PubMed: 8555956]

Ennett ST, Bauman KE. The contribution of influence and selection to adolescent peer group homogeneity: the case of adolescent cigarette smoking. Journal of Personality and Social Psychology. 1994; 67(4):653-663. [PubMed: 7965611]

Fergusson DM, Goodwin RD, Horwood LJ. Major depression and cigarette smoking: results of a 21year longitudinal study. Psychological Medicine. 2003; 33(8):1357-1367. [PubMed: 14672244]

Fergusson DM, Horwood LJ. The role of adolescent peer affiliations in the continuity between childhood behavioral adjustment and juvenile offending. Journal of Abnormal Child Psychology. 1996; 24(2):205-221. [PubMed: 8743245]

Flay BR, Hu FB, Siddiqui O, Day LE, Hedeker D, Petraitis J, Richardson J, Sussman S. Differential Influence of Parental Smoking and Friends' Smoking on Adolescent Initiation and Escalation and Smoking. Journal of Health and Social Behavior. 1994; 35(3):248-265. [PubMed: 7983337]

Fletcher AC, Jefferies BC. Parental Mediators of Associations between Perceived Authoritative Parenting and Early Adolescent Substance Use. The Journal of Early Adolescence. 1999; 19(4): 465-487.

Foxcroft DR, Lowe G. Adolescent drinking, smoking and other substance use involvement: links with perceived family life. Journal of Adolescence. 1995; 18(2):159-177.

Glendinning A, Shucksmith J, Hendry L. Family life and smoking in adolescence. Social Science \& Medicine. 1997; 44(1):93-101.

Go MH, Green HD, Kennedy DP, Pollard M, Tucker JS. Peer influence and selection effects on adolescent smoking. Drug and Alcohol Dependence. 2010; 109(1-3):239-242. [PubMed: 20071108] 
Gutman LM, Eccles JS, Peck S, Malanchuk O. The influence of family relations on trajectories of cigarette and alcohol use from early to late adolescence. Journal of Adolescence. 2011; 34(1):119128. [PubMed: 20129658]

Hall SM, Prochaska JJ. Treatment of Smokers with Co-Occurring Disorders: Emphasis on Integration in Mental Health and Addiction Treatment Settings. Annual Review of Clinical Psychology. 2009; 5:409-431.

Hawkins JD, Catalano RF, Miller JY. Risk and protective factors for alcohol and other drug problems in adolescence and early adulthood: implications for substance abuse prevention. Psychological Bulletin. 1992; 112(1):64-105. [PubMed: 1529040]

Hill KG, Hawkins JD, Catalano RF, Abbott RD, Guo J. Family influences on the risk daily smoking initiation. Journal of Adolescent Health. 2005; 37(3):202-210. [PubMed: 16109339]

Hoffman BR, Monge PR, Chou CP, Valente TW. Perceived peer influence and peer selection on adolescent smoking. Addictive Behaviors. 2007; 32(8):1546-1554. [PubMed: 17188818]

Holliday JC, Rothwell HA, Moore LA. The relative importance of different measures of peer smoking on adolescent smoking behavior: cross-sectional and longitudinal analyses of a large British cohort. Journal of Adolescent Health. 2010; 47(1):58-66. [PubMed: 20547293]

Hu FB, Flay BR, Hedeker D, Siddiqui O, Day LE. The Influences of Friends' and Parental Smoking on Adolescent Smoking Behavior: The Effects of Time and Prior Smoking. Journal of Applied Social Psychology. 1995; 25(22):2018-2047.

Isohanni M, Moilanen I, Rantakallio P. Determinants of teenage smoking, with special reference to non-standard family background. British Journal of Addiction. 1991; 86(4):391-398. [PubMed: 2054533]

Johnston, LD.; O’Malley, PM.; Bachman, JG.; Schulenberg, JE. Monitoring the Future national results on adolescent drug use: Overview of key findings, 2009. Bethesda, MD: National Institute on Drug Abuse; 2010.

Kobus K. Peers and adolescent smoking. Addiction. 2003; 98(Suppl 1):37-55. [PubMed: 12752361]

Kovacs, M. Children's Depression Inventory Manual. North Tonawanda: NY: Multi-Health Systems; 1992.

Kristjansson AL, Sigfusdottir ID, Allegrante JP, Helgason AR. Parental divorce and adolescent cigarette smoking and alcohol use: assessing the importance of family conflict. Acta Paediatrica. 2009; 98(3):537-542. [PubMed: 19021591]

Lambert NM, Hartsough CS. Prospective study of tobacco smoking and substance dependencies among samples of ADHD and non-ADHD participants. Journal of Learning Disabilities. 1998; 31(6):533-544. [PubMed: 9813951]

Latendresse SJ, Rose RJ, Viken RJ, Pulkkinen L, Kaprio J, Dick DM. Parenting mechanisms in links between parents' and adolescents' alcohol use behaviors. Alcoholism: Clinical and Experimental Research. 2008; 32(2):322-330.

Lloyd-Richardson EE, Papandonatos G, Kazura A, Stanton C, Niaura R. Differentiating stages of smoking intensity among adolescents: stage-specific psychological and social influences. Journal of Consulting and Clinical Psychology. 2002; 70(4):998-1009. [PubMed: 12182283]

MacPherson L, Strong DR, Kahler CW, Abrantes AM, Ramsey SE, Brown RA. Association of posttreatment smoking change with future smoking and cessation efforts among adolescents with psychiatric comorbidity. Nicotine and Tobacco Research. 2007; 9(12):1297-1307. [PubMed: 18058348]

Mayhew KP, Flay BR, Mott JA. Stages in the development of adolescent smoking. Drug and Alcohol Dependence. 2000; 59:S61-S81. [PubMed: 10773438]

Mercken L, Snijders TAB, Steglich C, Vertiainen E, de Vries H. Smoking-based selection and influence in gender-segregated friendship networks: a social network analysis of adolescent smoking. Addiction. 2010; 105(7):1280-1289. [PubMed: 20456296]

Milberger S, Biederman J, Faraone SV, Chen L, Jones J. ADHD is associated with early initiation of cigarette smoking in children and adolescents. The Journal of the American Academy of Child and Adolescent Psychiatry. 1997; 36(1):37-44.

Moos, RH.; Moos, BS. Family Environment Scale Manual. Palo Alto, CA: Consulting Psychologists Press, Inc; 1981. 
Myers MG, Brown SA. Cigarette smoking four years following treatment for adolescent substance abuse. Journal of Child \& Adolescent Substance Abuse. 1997; 7:1-15.

Prinstein MJ, Boergers J, Spirito A. Adolescents' and their friends' health-risk behavior: factors that alter or add to peer influence. Journal Pediatric Psychology. 2001; 26(5):287-298.

Prinstein MJ, La Greca AM. Childhood depressive symptoms and adolescent cigarette use: a six-year longitudinal study controlling for peer relations correlates. Health Psychology. 2009; 28(3):283291. [PubMed: 19450033]

Prinstein MJ, Nock MK, Simon V, Aikins JW, Cheah CS, Spirito A. Longitudinal trajectories and predictors of adolescent suicidal ideation and attempts following inpatient hospitalization. Journal of Consulting and Clinical Psychology. 2008; 76(1):92-103. [PubMed: 18229987]

Ramsey SE, Brown RA, Strong DR, Sales SD. Cigarette smoking among adolescent psychiatric inpatients: prevalence and correlates. Annals of Clinical Psychiatry. 2002; 14(3):149-153. [PubMed: 12585564]

Ramsey SE, Strong DR, Stuart GL, Weinstock MC, Williams LA, Tarnoff G, Picotte-Prillmayer DM, Brown RA. Substance use and diagnostic characteristics that differentiate smoking and nonsmoking adolescents in a psychiatric setting. Journal of Nervous and Mental Disease. 2003; 191(11):759-762. [PubMed: 14614345]

Riggs PD, Mikulich SK, Whitmore EA, Crowley TJ. Relationship of ADHD, depression, and nontobacco substance use disorders to nicotine dependence in substance-dependent delinquents. Drug and Alcohol Dependence. 1999; 54(3):195-205. [PubMed: 10372793]

Rohde P, Kahler CW, Lewinsohn PM, Brown RA. Psychiatric disorders, familial factors, and cigarette smoking: II. Associations with progression to daily smoking. Nicotine and Tobacco Research. 2004; 6(1):119-132. [PubMed: 14982696]

Santisteban DA, Coatsworth JD, Perez-Vidal A, Kurtines WM, Schwartz SJ, LaPerriere A, Szapocznik J. Efficacy of brief strategic family therapy in modifying Hispanic adolescent behavior problems and substance use. Journal of Family Psychology. 2003; 17(1):121-133. [PubMed: 12666468]

Shaffer D, Fisher P, Lucas CP, Dulcan MK, Schwab-Stone ME. NIMH Diagnostic Interview Schedule for Children Version IV (NIMH DISC-IV): description, differences from previous versions, and reliability of some common diagnoses. The Journal of the American Academy of Child and Adolescent Psychiatry. 2000; 39(1):28-38.

Simons-Morton BG. Prospective analysis of peer and parent influences on smoking initiation among early adolescents. Prevention Science. 2002; 3(4):275-283. [PubMed: 12465590]

Simons-Morton BG. The protective effect of parental expectations against early adolescent smoking initiation. Health Education Research. 2004; 19(5):561-569. [PubMed: 15150137]

Simons-Morton BG, Farhat T. Recent findings on peer group influences on adolescent smoking. Journal of Primary Prevention. 2010; 31(4):191-208. [PubMed: 20614184]

Smucker MR, Craighead WE, Craighead LW, Green BJ. Normative and reliability data for the Children's Depression Inventory. Journal of Abnormal Child Psychology. 1986; 14(1):25-39. [PubMed: 3950219]

SPSS Inc. SPSS for Windows (Version Rel. 17.0.3). Chicago: 2009.

Substance Abuse and Mental Health Services Administration. Results from the 2009 National Survey on Drug Use and Health: Volume I. Summary of National Findings (Office of Applied Studies, NSDUH Series H-38A, No. HHS Publication No. SMA 10-4586). Rockville, MD: 2010.

Tilson EC, McBride CM, Lipkus IM, Catalano RF. Testing the interaction between parent-child relationship factors and parent smoking to predict youth smoking. Journal of Adolescent Health. 2004; 35(3):182-189. [PubMed: 15313499]

Tucker JS, Ellickson PL, Klein DJ. Predictors of the transition to regular smoking during adolescence and young adulthood. Journal of Adolescent Health. 2003; 32(4):314-324. [PubMed: 12667736]

Turner L, Mermelstein R, Flay B. Individual and contextual influences on adolescent smoking. Annals of the New York Academy of Sciences. 2004; 1021:175-197. [PubMed: 15251888]

Tyas SL, Pederson LL. Psychosocial factors related to adolescent smoking: A critical review of the literature. Tobacco Control. 1998; 7:409-420. [PubMed: 10093176]

U.S. Department of Health and Human Services. Preventing Tobacco Use Among Young People: A Report of the Surgeon General. Atlanta, GA: U.S. Department of Health and Human Services, 
Public Health Service, Centers for Disease Control and Prevention, National Center for Chronic Disease Prevention and Health Promotion, Office on Smoking and Health; 1994.

Upadhyaya HP, Brady KT, Wharton M, Liao J. Psychiatric disorders and cigarette smoking among child and adolescent psychiatry inpatients. American Journal of Addicitions. 2003; 12(2):144-152.

Upadhyaya HP, Deas D, Brady KT, Kruesi M. Cigarette smoking and psychiatric comorbidity in children and adolescents. The Journal of the American Academy of Child and Adolescent Psychiatry. 2002; 41(11):1294-1305.

Wang MQ, Fitzhugh EC, Westerfield RC, Eddy JM. Family and peer influences on smoking behavior among American adolescents: an age trend. Journal of Adolescent Health. 1995; 16(3):200-203. [PubMed: 7779829]

Windle M, Windle RC. Depressive symptoms and cigarette smoking among middle adolescents: Prospective associations and intrapersonal and interpersonal influences. Journal of Consulting and Clinical Psychology. 2001; 69(2):215-226. [PubMed: 11393599] 


\section{Table 1}

Cigarette Use in a Sample of Psychiatrically Hospitalized Adolescents

\begin{tabular}{lcc}
\hline & Baseline n (\%) & 18 Month Follow-up n (\%) \\
\hline Lifetime Cigarette Use & & \\
$\quad$ No use & $54(51 \%)$ & $21(23 \%)$ \\
$\quad$ Smoked at Least 1 Cigarette & $52(49 \%)$ & $72(77 \%)$ \\
Past 30 Day Use & & \\
No Use & $68(64 \%)$ & $40(49 \%)$ \\
Smoked at Least 1 Day & $38(36 \%)$ & $41(51 \%)$ \\
\hline
\end{tabular}


Table 2

Summary of Study Variables for Adolescent Psychiatric Patients at Baseline $(n=106)$

\begin{tabular}{ll}
\hline Variable & Mean (SD) \\
\hline Psychological Symptoms & $19.81(9.43)$ \\
Depressive Symptoms (CDI) & \\
Conduct problem symptoms- & \\
$\quad$ Adolescent-report & $3.34(3.47)$ \\
$\quad$ Parent-report & $6.20(3.65)$ \\
Close Friend Use/Attitudes & $.43(.34)$ \\
$\%$ friends who smoke cigarettes & $.41(.35)$ \\
\% friends who got drunk & $.39(.38)$ \\
$\%$ friends who smoke marijuana & $.48(.39)$ \\
$\%$ friends who disapprove of use & \\
Family Environment Scale & $39.24(18.69)$ \\
Cohesion & $58.34(13.72)$ \\
Conflict
\end{tabular}


